\begin{tabular}{|c|}
\hline Pre-print \\
Submitted to Anthropology Today (February 2016) \\
http://onlinelibrary.wiley.com/journal/10.1111/(ISSN)1467-8322 \\
Not for citation \\
\hline
\end{tabular}

\title{
Cooperation and Competition in Social Anthropology
}

José Luis Molina, Miranda J Lubbers, Hugo Valenzuela-García \& Sílvia Gómez-Mestres, GRAFO, Department of Social And Cultural Anthropology, Universitat Autònoma de Barcelona

\begin{abstract}
The emergence of cooperation and altruism in human societies has received ample academic attention from different disciplines, and is usually considered as an adaptive response to competition over scarce resources. In this article, we review the specific contribution that social anthropology has made to this field of research. We propose that social anthropology has contributed to this field through the description of the systems that have regulated both cooperation and competition in traditional societies: (1) hunter-gatherer societies, where generalized reciprocity dominated, (2) prestige economies, which includes exchange of valuables in specific spheres, primitive money, agonistic institutions in tribes, and last, (3) "moral economies" in peasant communities, where cooperation and competition coexist but never at the cost of putting at risk the reproduction of the community itself or of some of its members. The three systems share the basic mechanism of reciprocity that allow for the maintenance of equality, and large social networks in foraging societies, as well as the very language for regulating competition in unequal prestige or moral economies. This pervasive presence of reciprocity either as actual behaviour or as a moral norm reveals its basic role in the human evolution, and, likely, its co-evolution with ritual forms of social exchange.
\end{abstract}

\section{Introduction}

Why do humans cooperate so extensively? This intriguing question has been advanced from a variety of disciplines including biology, economics, archaeology and evolutionary and social anthropology, and each one has contributed with different pieces to the puzzle. In this article we wish to highlight the specific contribution that social and cultural anthropology has made to this field of research. In order to do so, we will first review the basic mechanisms explaining cooperation as identified in the larger literature. We then observe that social anthropology investigates cooperation and competition from a different angle than is common in the larger literature, and subsequently, we will describe the contribution of social and cultural anthropology to this field. In our conclusion, we will summarize our review and give some suggestions for further research. 
In an attempt to understand why humans cooperate on such a broad scale, the literature generally distinguishes between three primary mechanisms for the evolution of cooperation: kin selection, reciprocity and group selection. The first mechanism, kin selection, stems from evolutionary biology and interprets the Darwinian theory of natural selection from the point of view of the gene. This approach assumes that it is not the individual who acts selfishly in its attempt to survive, but the gene (Dawkins 1976). In line with this assumption, the hypothesis of "inclusive fitness" (Hamilton 1964) stipulates that natural selection can favour altruistic behaviours when the donor and the recipient are genetically related, and when the degree of relatedness exceeds the cost-benefit ratio of altruism. Related research on kin selection has proposed, among others, the so-called "grandmother hypothesis" (Hawkes et al. 1998) that explains the long postmenopausal lifespans that distinguish humans from all other primates as an adaptive way to enhance daughters' fertility through food sharing and additional care provided by their mothers after menopause. This hypothesis has faced strong criticism (Kennedy 2003; Peccei 2001; Zeller 2004, among others) since adults older than 40 years were very rare in Prehistoric times.

The second mechanism, reciprocity, focuses on the individual as the unit of fitness in the theory of natural selection. Rather than focusing on altruism, it focuses on mutualistic cooperation as an individual strategy for more effective competition. Several mechanisms of reciprocity have been proposed and tested from an individual cost-benefit perspective. The first is direct reciprocity (i.e., A helps B and B, subsequently, returns the favour). Evolutionary game theory has modelled direct reciprocity with the Prisoner's Dilemma and the Iterated Prisoner's Dilemma (Axelrod and Dion 1988; Axelrod and Hamilton 1981). Results suggested that in a single encounter between two individuals, it may be more beneficial for each individual to defect than to cooperate, but if two individuals are to meet repeatedly, cooperation may be more beneficial to each of them. Therefore, and according to this line of argument, for direct reciprocity to occur the probability of a new encounter must exceed the cost-benefit ratio of cooperation. Indirect reciprocity, on the other hand, situates pair-wise interactions in a larger group context and explains why persons may also help others asymmetrically (Nowak and Sigmund 2005). It specifies that the favour to be returned may be generalized to include other individuals. More specifically, if A helps B, the favour may later be returned by $\mathrm{C}$ helping A or $\mathrm{B}$ helping C. Indirect reciprocity is a cognitively more demanding mechanism, since it requires individuals to not only remember their own interactions, but also monitor the interactions in the larger group. It also relies on language for the transmission of information about those interactions. Indirect reciprocity is thought to lead to the evolution of morality and social norms. Finally, the mechanism of network reciprocity has been proposed (Nowak 2006). This mechanism pays more detailed attention to the role of the group context, as it recognizes that 
individuals do not interact in random ways but rather their interactions depend on the specific configuration of the social network. Evolutionary games (e.g., Hanaki et al. 2007; Gianetto \& Heydari 2015) indeed show that the social structure of the group, in particular its modularity, strongly affects the evolution of cooperative behaviour.

These three mechanisms of reciprocity have been tested with simulations and agentbased modelling inspired by the Prisoner-Dilemma games developed by neoclassical economics, which poses that individual agency and the prosecution of individual interest are the basis for explaining human societies. Darwinist theories and neoclassical economics share the common understanding of human nature and society as an individual-driven affaire, even if its dynamics lead to the emergence of complex social structures. Despite the valuable contributions stemming from this perspective, some researchers criticized purely individual explanations of cooperation as oversimplifications of human evolution and argued for a larger consideration of collaborations among group members and among groups in the evolution of cooperation (e.g.,Fuentes 2004).

In this latter regard, Tomasello et al. (2012) have proposed two steps in the evolution of human cooperation. In the first step, humans became obligate foragers so that individuals became interdependent on each other and started to have a direct interest in the well-being of their group members. Tomasello and his colleagues describe the dilemma of cooperation in this setting as a Stag Hunt rather than the more conventional Prisoner's Dilemma: hunting for greater animals (a stag) would be more beneficial for all participants than just hunting for smaller animals (say, a hare), but it requires collaboration. In this setting of collaborative foraging (in tandem with cooperative breeding; Hrdy 2009; Kaplan et al. 2000), humans developed new skills, both technological and social, as well as shared intentionality. In a second step, these new skills and motivations were scaled up to life in larger groups that included relative strangers, as more sedentary forms of living implied larger group sizes and larger intergroup competition. Coordination and cooperation became more complex, bringing in the need for creating social norms, institutions and practices that underline group mindedness. Tomasello et al. argue that while kin selection and reciprocity undoubtedly play a role, it is really the interdependence of group members and social selection based on reputation as a good collaborator that drove the evolution of collaboration.

Whatever the precise perspective considered so far, the common problem considered is the emergence of altruistic and cooperative behaviours as opposed to "natural" ones (i.e., competitive). Social anthropology, however, tackles this issue in a completely different manner. First, social anthropology has traditionally considered reciprocity, cooperation and the universal moral norm to return favours as the starting point for every known human community (Mauss 1924). In other words, cooperation is not regarded as an adaptive answer to competition. 
Second, social anthropology has contributed with empirical research in many societies of different types, showing the overall copresence of competition and cooperation, and the ways in which the two mechanisms are related, regulated and balanced.

To illustrate this, in the next section we will highlight social anthropological theories that touch directly upon the theme of cooperation and competition in three different types of societies: hunter-gatherers, tribal, and peasant societies.

\section{Hunter-gatherers: generalized reciprocity and social equality}

In hunter-gatherer societies, the band is the basic social organization unit. In a cross-cultural study of 32 hunter-gatherer societies, Hill et al. (2011) found that bands are on average composed of 28 band members, although the band size varies considerably across societies. In contrast to what was assumed earlier (and in contrast to kin selection theories), they further found that bands are typically composed of both related and unrelated individuals, and that individuals tend to visit other groups frequently, facilitating friendly intergroup interactions.

The anthropological literature on hunter-gatherer bands has identified generalized reciprocity and egalitarianism as their dominant features (Godelier 1974; Lee and DeVore 1968). Generalized reciprocity (Sahlins 1972) differs from direct reciprocity in that an altruistic transaction takes place with no expectations about the timing of the return transaction or about its precise qualities or quantities. It implies the lack of an accounting system of exchanges, and, at the same time, the continuous redistribution of wealth and food among the band members. Empirical research has shown that these exchanges are not only frequent among members of the same band, but also among members from different bands, normally --but not exclusively-- kin. For example, Hill (2002) summarizes the complex system of exchanges of meat among the Ache with the simple rule "cooperate frequently and share fully". This illustrates that the social organization of foraging peoples seems to be primarily intended to prevent competition and social inequality, by stressing cooperation and sharing as the appropriate behaviours through these basic mechanisms. Schweizer et al. (1997) pointed out the importance of the expressive network of gift-giving among the !Kung of the Kalahari desert for connecting distant places at a regional level, and for introducing Western products in the network of exchanges, integrating thus this supposed pristine society in the large global world. Schweizer focused on the hxaro institution, which prescribes reciprocal gift exchanges among kin, but a recent analysis of the network of gift giving among the Hadza of Tanzania (Apicella et al. 2012) shows the same widespread phenomenon of gift exchanges both among kin and non-kin, again both within and among places. The structural properties of social networks elicited by gift-giving exchange among the Hadza showed striking resemblances with the networks of modern individuals, namely strong tendencies of reciprocity (a tendency to give to people who give to you), 
transitivity (a tendency to give to people who others that you are related with also give to), a skewed degree distribution (i.e., a few individuals have many more exchange relationships than the others), degree assortativity (i.e., individuals tend to exchange gifts with others who exchange with similar numbers of others), geographic decay (less gift-giving relationships over larger distances) and homophily (the tendency to exchange with people who are similar). This led Apicella et al. to conclude that social networks played an important role in the evolution of cooperative behaviour. The development and maintenance of large social networks within and across bands is possible due to the basic mechanism of generalized reciprocity. This mechanism applies both to food sharing, and gift-giving exchanges, the expressive side of long-term relationships.

Apart from the resemblance of social networks of modern individuals with those of hunter-gatherers, the importance of the value of generalized reciprocity in human evolution can also still be observed today in the basic values stressed by etiquette codes, education, and religious precepts all over the world. The existence of a set of basic values is what Graeber (2011) calls "Baseline Communism", i.e., the moral obligation of sharing the resources available to the small group on the basis of equality, which he considered to be "the raw material of sociality". Again we could consider this phenomenon as a product of human evolution.

In sum, foraging societies exhibit basic characteristics that are still present in today's complex societies, such as the tendency to promote cooperation and prevent competition in small groups, the maintenance of large and de-localized social networks through gift-giving exchanges. The basic mechanism underpinning these processes, generalized reciprocity, is regarded by hierarchical societies as the language for regulating actual competition. We will pay attention to this issue in the next section.

\section{Tribes: Prestige Economy, Agonistic Institutions, and Primitive Money}

Tribal societies, most of them nowadays living in the tropics, rely typically on slash-and-burn agriculture and/or nomadic grazing of cattle. These societies are typically much larger and have more hierarchical organization systems that have to be renewed under conditions of extreme competition.

In tribal societies, social stratification and inequality become more important. The main mechanism for the reproduction of inequality is the accumulation and distribution of wealth by individuals in order to acquire prestige within the group, the so-called "Big Man" institution (Godelier 1982). This competition for prestige is frequently regulated through agonistic institutions, i.e., competitive ceremonies in which the winner is able to redistribute more wealth and gifts, even to enemies. In this regard, potlatch and moka constitute classical ethnographic 
examples of such competitive exchanges in prestige economies (Piddocke, 1965; Godelier, 1996).

The existence of at least two differentiated spheres of exchange in all societies with some degree of social stratification can be interpreted in the same way: the subsistence sphere is intended to maintain an egalitarian morale, whereas the prestige sphere provides the means for regulated competition, and the development of inequality (Bohannan and Dalton 1965). In the case of the Tiv of Nigeria, for instance, the prestige sphere was regulated through the presence of a limited number of brass rods in a way that who owned one of them had access to one of the available positions in this society. "Primitive money", objects with just one or two monetary functions (i.e. accumulation and/or mean of payment), has been interpreted as tokens of the actual prestigious positions available to a given society, funnelling conflicts towards this specific domain. In the words of Mary Douglas, primitive money is not supposed to circulate but to control (competition in this case; Douglas 1967).

The huge diversity of valuables exchanged in tribal societies would represent another example of prestige competition regulation. The best known example is the kula ring described by Malinowski in The Argonauts of the Western Pacific (1922). The kula ring refers to gift economy in the Trobriand Islands where non-use items that are considered valuable are exchanged as gifts, in order to one's enhance social. Again the language is formal reciprocity, i.e., the obligation to repay in the future a favour received in a not predetermined form, but the goal is to acquire the most precious valuables managing the delayed exchanges without compromising trust. The existence of intermediate gifts facilitates this game (Ziegler 2008).

We can also see that the prestige sphere is associated with a good amount of ritual. In his seminal work about the role of ritual in the evolution of mankind (Rappaport 1999), Rappaport suggest that society and religion share a common origin in ritual. In non-human societies, rituals refer to set of simplified and exaggerated behaviours that are performed in other contexts of interaction different from the original function (i.e. the way domestic dogs lick human companions in greeting resembles canid pups begging food from adults, see Watanabe and Smuts 1999). Likewise, in human societies ritual involves a series of repetitive invariant conventions independent from the will of participants, which have to be performed, not just acknowledged. Ritual, then, embodies at the same time authority (the canon), acquiescence (acceptance of the norm while performing it), and possibly, sacred truth, a constitutive part of the language itself. The social order resulting from the ritual celebration promises future cooperation and reciprocity, the very first social contract. We suggest that this hypothesis about the evolutionary origin of cooperation would explain the pervasive reference to reciprocity in more elaborated and competitive social systems. 
From the previous examples we can see that cooperation and competition coexist in tribal societies, and how competition is regulated through different institutions. Now, we shall pay attention to the concept of moral economy in peasant societies.

\section{Peasants: Moral Economy}

Peasant societies have been described in their enormous diversity as societies that are part of states that practice intensive agriculture with at least some cash crops intended for the market (Wolf 1955). The concept of moral economy was first suggested by the Russian economist Alexander Chayanov (1966). It was popularized by E. P. Thompson (1971) in his study of the riots that took place in the English countryside in the late $18^{\text {th }}$ century and it was also successfully applied to the analysis of South-East Asian peasantry by James C. Scott (1976). In a nutshell, a moral economy is an economy based on fairness. Rather than maximizing profits, the principle of a moral economy is that the reproduction of the community and its members is paramount. This principle implies that peasants are dominated by definition, that they revolt just when their livelihood is jeopardized, and that they exert an everyday resistance in the form of petty theft, passive boycotting, looting, and vandalism in order to undermine the authority of those who threaten the community, the "weapons of the weak" (Scott 1985).

The notion of moral economy explains the existence of a wide range of phenomena, both inside of outside of the peasant world. The first phenomenon is the existence of cooperative institutions, normally arranged on a rotating basis, for gathering workforce during

the harvest or when major works are necessary (Barth 1967). The acknowledgement of a "moral community" legitimates the functional value of these institutions, even among distant neighbours. The second phenomenon is the investment in ritual expenses, either cargo systems or community celebrations. These investments can be considered as competition in the sphere of prestige or redistributive institutions, and a way to claim a role in the politics of the community. Besides, these rituals are being considered as a way to prevent the entrance of strangers in the community (Wolf 1955). The third phenomenon is the acceptance of patron-client relationships as a convenient arrangement when the subsistence is not fully guaranteed. With the term patronclient relationship, we refer to a dyadic and asymmetric relationship in which an individual of high status (a patron) uses his influence and resources to protect another individual of lower status (the client), in exchange for support and loyalty. This relationship is unequal, personal and informal (Scott 1976). Again, the expressive language of reciprocity is used for explaining these asymmetric exchanges among the patron and the client. Likewise, in situations of scarcity (like the one experimented by the late Soviet Union during the last quarter of the $20^{\text {th }}$ Century, or in some post-socialist countries) these informal arrangements among individuals were understood under the label of "Economy of Favours" (Ledeneva 1998). Finally, this notion allows explaining the close coexistence of competition and cooperation in regular activities. 
People can compete for land, water, better prices or bargaining with their peers, but never to the extreme of annihilating the opponent. Outside the peasant world, similar observations have been made. For example, the cut-throat competition among compatriots in ethnic enclaves sharing the same economic niche does not prevent the existence of mutual help in case of extreme need (Valenzuela-Garcia et al. 2014).

\section{Conclusions}

In the study of cooperation, social anthropologists have provided ample evidence that cooperation has not only emerged as an answer to competition but that the two coexist in every society. Also, ethnographies have observed that cooperation does not only occur within groups, but also between groups, and not only with kin but also with non-kin.

The existence of cooperation as a trend of human evolution is especially apparent in foraging societies, where the whole social organization is designed to prevent competition and conflict, while stressing food sharing and collaboration. Transdisciplinary collaboration among ethnographers of foraging societies and social network analysts have shown the importance of social networks and the gift-giving mechanism as basic factors explaining the evolution of human cognition and the maintenance of equality in these societies. The basic rule of reciprocity, i.e., deferred repayment of a favour or gift in a non-predetermined form, explains not only the actual exchanges among hunter-gatherers, but also the expressive form of unequal and competitive exchanges in stratified societies. The fact that the language of reciprocity is used in asymmetrical exchanges like patron-client relationships or in convenience exchanges in the "economy of favours" tell us of its paramount importance for human society. We have suggested that Rappaport (1999) provided a probable explanation of this fact by linking reciprocity and ritual as the primitive forms of (sacred) social contract. Furthermore, competition and inequality have been historically regulated through the emergence of specific fields (prestige spheres) or agonistic institutions, redistributive in their essence. Finally, the acknowledgement of a "moral community" by their members has consequences both for the existence of cooperative institutions and for the regulation of competition in order to preserve the reproduction of the community. The moral norm of reciprocity tells us the simple and powerful principle that our social ties today will last in the future, or, in order words, that the current social structure will last into the future.

As we have tried to demonstrate, anthropological evidence has shown that cooperation and collaboration coexist in all societies known to mankind, and has described the multiple ways in which their interaction is regulated. While agent-based modelling based on evolutionary game theory, multilevel selection theories and network reciprocity have greatly advanced earlier, simpler simulations of the Prisoner's dilemma, we would suggest that future research 
explores the co-existence of cooperation and competition in different dimensions, instead of modelling the two as each other's opposites (cooperator versus defector). We believe that such perspectives might add further complexity and therefore a better understanding of the phenomenon of cooperation and the institutions that regulate it.

\section{References}

Apicella, Coren L., Frank W. Marlowe, James H. Fowler, and Nicholas a Christakis. 2012. "Social Networks and Cooperation in Hunter-Gatherers." Nature 481(7382):497-501.

Axelrod, R., and D. Dion. 1988. "The Further Evolution of Cooperation." Science (New York, N.Y.) 242:1385-90.

Axelrod, R., and W. D. Hamilton. 1981. "The Evolution of Cooperation." Science 211(4489):1390-96. Retrieved (http://www.sciencemag.org/content/211/4489/1390.abstract).

Barth, Fredrik. 1967. "Economic Spheres in Darfu." in Themes in Economic Anthropology, edited by Raymond Firth. London: Tavistock Publications.

Bohannan, Paul, and George Dalton. 1965. Markets in Africa. Eight Subsistence Economies in Transition. New York: Doubleday Anchor.

Dawkins, Richard. 1976. The Selfish Gene. Oxford: Oxford University Press.

Douglas, Mary. 1967. "Primitive Rationing. A Study in Controlled Exchange." Pp. 119-32 in Themes in Economic Anthropology, edited by Raymond Firth. London: Associations of the Social Anthropologist of the Commonwealth.

Fuentes, Agustin. 2004. "It' S Not All Sex and Violence: Integrated Anthropology and the Role of Cooperation and Social Complexity in Human Evolution." American Anthropologist 106(4):710-18.

Godelier, Maurice. 1974. Un Dómaine Contesté: L'anthropologie économique. Paris: École Pratique des Hautes Études.

Godelier, Maurice. 1982. La Production Des Grands Hommes. Pouvoir et Domination Masculine Chez Les Baruya de Nouvelle-Guinée. Paris: Fayard.

Godelier, Maurice. 1996. L'ènigme Du Don. Paris: Fayard.

Graeber, David. 2011. Debt. The First 5.000 Years. New York: Melville House Publishing.

Hamilton, W. D. 1964. "The Genetical Evolution of Social Behaviour." Journal of Theoretical Biology 7(1):1-16.

Hawkes, Kristen, James F. O’Connell, Nicholas G. Blurton Jones, H. Alvarez, and E. L. Charnov. 1998. "Grandmothering, Menopause, and the Evolution of Human Life Histories." Proceedings of the National Academy of Sciences 95(February):1336-39.

Hill, Kim. 2002. "Altruistic Cooperation during Foraging by the Ache, and the Evolved Human Predisposition to Cooperate." Human Nature : An Interdisciplinary Biosocial Perspective 13(1):105-28.

Hrdy, Sarah Blaffer. 2009. Mothers and Others: The Evolutionary Origins of Mutual Understanding. Cambridge, MA: Harvard University Press.

Kaplan, Hillard, Kim Hill, Jane Lancaster, and A. Magdalena Hurtado. 2000. "A Theory of Human Life History Evolution: Diet, Intelligence, and Longevity." Evolutionary Anthropology: Issues, News, and Reviews 9(4):156-85.

Kennedy, G. E. 2003. "Palaeolithic Grandmothers? Life History Theory and Early 'Homo."” 
The Journal of the Royal Anthropological Institute 9(3):549-72.

Ledeneva, Alena V. 1998. Russia's Economy of Favours. Blat, Networking and Informal Exchange. Cambridge: Cambridge University Press.

Lee, Richard Barry, and Irven DeVore. 1968. Man the Hunter. New Jersey: Aldine Transaction.

Nowak, Martin A. 2006. "Five Rules for the Evolution of Cooperation." Science 314(5805):1560-63.

Nowak, Martin A., and Karl Sigmund. 2005. "Evolution of Indirect Reciprocity.” Nature 437(7063):1291-98. Retrieved (http://dx.doi.org/10.1038/nature04131).

Piddocke, Stuart. 1965. "The Potlach Systemof Southern Kwakiutl: A New Perspective." Southwestern Journal of Anthropology 21(3):244-64.

Rappaport, Roy A. 1999. Ritual and Religion in the Making of Humanity. Cambridge : Cambridge University Press.

Schweizer, Thomas et al. 1997. "Embeddedness of Ethnographic Cases A Social Networks Perspective." Current Anthropology 38(5):739-60.

Scott, James C. 1976. The Moral Economy of the Peasant. Rebellion and Subsistence in Southeast Asia. New Haven \& London: Yale University Press.

Scott, James C. 1985. Weapons of the Weak. Everyday Forms of Peasant Resistance. London and New Haven: Yale University Press.

Thompson, E. P. 1971. "The Moral Economy of the English Crowd in the Eighteenth Century." Past and Present 50:76-136.

Tomasello, Michael, Alicia P. Melis, Claudio Tennie, Emily Wyman, and Esther Herrmann. 2012. "Two Key Steps in the Evolution of Human Cooperation: The Interdependence Hypothesis." Current Anthropology 53(6):673-92.

Watanabe, John M., and Barbara B. Smuts. 1999. "Explaining Religion without Explaining It Away: Trust, Truth, and the Evolution of Cooperation in Roy A. Rappaport's 'The Obvious Aspects of Ritual."” American Anthropologist 101(1):98-112.

Wolf, Eric R. 1955. "Types of Latin American Peasantry: A Preliminary Discussion.” American Anthropologist 57:452-71.

Ziegler, Rolf. 2008. "What Makes the Kula Go Round?” Social Networks 30(2):107-26. 